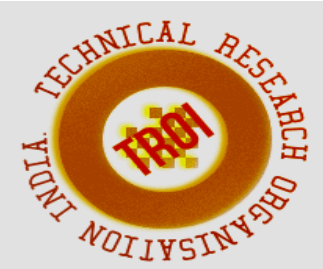

\title{
“WAR FIELD SYPING ROBOT WITH NIGHT VISION WIRELESS CAMERA USING ANDROID APPLICATIONS”s
}

\author{
Ashwini $\mathrm{V}^{1}$, AsmaSadia $\mathrm{M}^{2}$, SherishaN ${ }^{3}$,Mr.Ronald Lawrence $\mathrm{J}^{4}$,Mrs. Jillian Rufus $\mathrm{J}^{5}$ \\ 1,2,3 UG Student, Dept of EEE, Dr. TTIT, KGF \\ ${ }^{4,5}$ Assistant Professor, Dept of EEE, Dr. TTIT, KGF \\ ashwini9198@gmail.com ${ }^{1}$,asma.m310197@gmail.com², sherishan9535@gmail.com³, \\ media@drttit.edu.in ${ }^{4}$,jillian@drttit.edu.in ${ }^{5}$
}

\section{Abstract}

The main objective for developing the robot is for the surveillance of human activities in the war field or rescue operations in order to reduce attacks from the enemy side. The robot consists of night vision wireless camera which can transmit videos of the war field in order to prevent any damage and loss to human life. Military men have a huge risk on their lives while entering an unknown territory. The robot will serve as an appropriate machine for the defence sector to reduce the loss of human life and will also prevent illegal activities. It will help all the military people and armed forces to know the condition of the territory before entering it. This can also be used in various rescue operations to save the man power and to monitor hazardous situations. The main advantage of this project is that we can easily control the robot using an android mobile by a blynk app. An ArduinoATMEGA2560 is used for the desired operation. A smart cell phone with IP web cam application is mounted on the robot body for spying purpose even in complete darkness by using infrared lighting. This will send the videos wirelessly at the transmitter side (laptop). This is kind of robot can be helpful for spying purpose in war fields and in order to minimize the attacks like 26/11 in Mumbai in future. It can also be helpful where living beings cannot reach.

Key Words: Robot, War Spying robot, Airdroid app (Smart Cell Phone).

\section{INTRODUCTION}

With the aim of developing a high-tech technology that serves high speed technology, advanced capacity to control the robots and to device new methods of control theory. To realize above standards some technical improvement along with the need of high performance robot is required to create a faster, reliable, accurate and more intelligent robot which can be devised by advanced control algorithm, robot control devices and new drivers.

Earlier the robots were controlled through wired networks but now to make robot more users friendly, they are framed to make user commanded work. Therefore to attain the requirements we can use android as a multimedia to control the user friendly robot.

The design of our project encourages developing a robotic vehicle based on IOT technology for the remote operation connected with the wireless camera mounted on the robot for monitoring purpose. The robot is embedded with ardiunoATMEGA2560 for desired operation and is generally used for spying purposes. The transmitting module consist of the push buttons that send the commands to the receiving module for controlling the movement of robot either to right, left, forward, downward. Basically the project is designed to develop a robotic vehicle named War Field Spying Robot using IOT technology for remote operation attached with smart cell phone having Airdroid application for monitoring purpose. The robot along with smart cell phone can wirelessly transmit real time video and will give confidential information regarding opposite parties. 


\section{PROBLEM OBJECTIVES}

1) To design a robot.

2) To capture the videos at the night using night vision camera.

3) Monitoring using IOT Technology.

4) To monitor the night activities at the war field.

5) To control the robot wirelessly

\section{METHODOLOGIES} ADOPTED

1) Study of hardware materials used in project.

2) Implementation of hardware models.

3) Study of software used in the project.

4) Implementation of software coding.

5) Installing various hardware components.

\section{SYSTEM REQUIREMENTS AND SPECIFICATIONS}

Hardware requirements

1. Arduinoatmega 2560

2. Dc Motor

3. Metal Sensor

4. Air Quality Sensor M2132

5. Carbon monoxide gas sensor

6. Stepper Motor

7. Motor Driver L293d

8. Lithium Ion Battery

Software requirements

BLYNK - Smartphone Google play Application for IOT

Sketch IDE - Programming Arduino MEGA-2560

\section{BLOCK DIAGRAM}

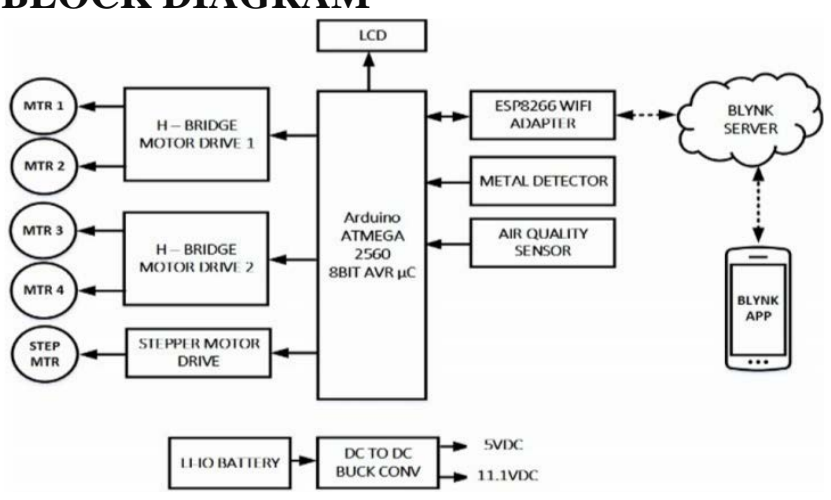

Figure 1: BLOCK DIAGRAM OF CONTROLLER AND TRANSMITTER RECEIVER UNIT

\section{ARDUINO MEGA-2560}

Arduino is a tool for making computers that can sense and control more of the physical world than your desktop computer. It's an open-source physical computing platform based on a simple microcontroller board, and a development environment for writing software for the board. Arduino can be used to develop interactive objects, taking inputs from a variety of switches or sensors, and controlling a variety of lights, motors, and other physical outputs. Arduino projects can be stand-alone, or they can be communicating with software running on your computer (e.g. Flash, Processing, and Max MSP.) The boards can be assembled by hand or purchased preassembled; the opensource IDE can be downloaded for free. The Arduino programming language is an implementation of Wiring, a similar physical computing platform, which is based on the Processing multimedia programming environment.

Example of different arduino boards

$\square$ ArduinoDiecimila
$\square$ ArduinoDuemilanove
$\square$ Arduino UNO
$\square$ Arduino Leonardo
$\square$ Arduino Mega
$\square$ Arduino Mega ADK
$\square$ Arduino Nano
$\square$ Arduino Pro-Mini
$\square$ Arduino Due ( ARM-based )

2. METAL DETECTORS

Metal detectors can detect nearly all metallic objects. That means anything that contains elements like gold, silver, iron, nickel, copper, aluminium, tin and lead or mixtures and combinations like bronze and brass. Metal detectors cannot detect non-metal items such as wood, plastic, stones and bone. Some metal detectors are able to discriminate which means that they can differentiate between various types of metal.

Like everything there is more than one way to detect metal and thus more than one way to make a metal detector. There are three main types of metal detectors that are available. Metal detectors use electromagnetic induction to detect metal. Uses include de-mining (the detection of land mines), the detection of weapons such as knives and guns, especially at airports, geophysical prospecting, archaeology and treasure hunting. Metal detectors are also used to detect foreign bodies in food, and in the construction industry to detect steel reinforcing bars in concrete and pipes and wires buried in walls and floors. 


\section{MOTOR CONTROLLER}

A motor controller is a device or group of devices that serves to govern in some predetermined manner the performance of an electric motor. A motor controller might include a manual or automatic means for starting and stopping the motor, selecting forward or reverse rotation, selecting and regulating the speed, regulating or limiting the torque, and protecting against overloads and faults.

\section{H BRIDGE}

An $\mathbf{H}$ bridge is an electronic circuit that switches the polarity of a voltage applied to a load. These circuits are often used in robotics and other applications to allow DC motors to run forwards or backwards.

Most DC-to-AC converters (power inverters), most AC/AC converters, the DC-to-DC pushpull converter, most motor controllers, and many other kinds of power electronics use $\mathrm{H}$ bridges. In particular, a bipolar stepper motor is almost invariably driven by a motor controller containing Two $\mathrm{H}$ Bridges.

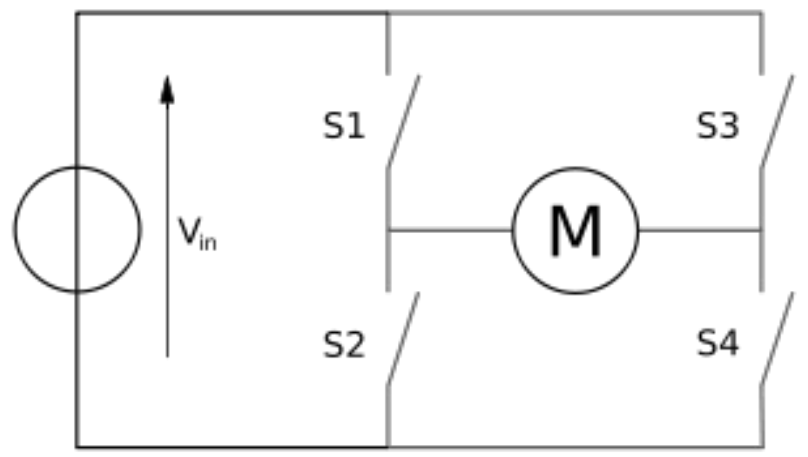

The term "H-bridge" is derived from the typical graphical representation of such a circuit. An Hbridge is built with four switches (solid-state or mechanical). When the switches S1 and S4 (according to the first figure) are closed (and S2 and S3 are open) a positive voltage will be applied across the motor. By opening S1 and S4 switches and closing S2 and S3 switches, this voltage is reversed, allowing reverse operation of the motor.

Using the nomenclature above, the switches S1 and S2 should never be closed at the same time, as this would cause a short circuit on the input voltage source. The same applies to the switches S3 and S4. This condition is known as shootthrough.

\begin{tabular}{|c|c|c|c|c|}
\hline S1 & S2 & S3 & S4 & Result \\
\hline 1 & 0 & 0 & 1 & $\begin{array}{l}\text { Motor moves } \\
\text { Clock wise }\end{array}$ \\
\hline 0 & 1 & 1 & 0 & $\begin{array}{c}\text { Motor moves anti } \\
\text { Clock wise }\end{array}$ \\
\hline 0 & 0 & 0 & 0 & Motor free runs \\
\hline
\end{tabular}

\section{MOTOR DRIVE IC L293D}

L293D is a typical Motor driver or Motor Driver IC which allows DC motor to drive on either direction. L293D is a 16-pin IC which can control a set of two DC motors simultaneously in any direction. It means that you can control two DC motor with a single L293D IC.Dual H-bridge Motor Driver integrated circuit (IC).The 1293d can drive small and quiet big motors as well.

The L293D is a quadruple high-current half-H driver designed to provide bidirectional drive currents of up to $600-\mathrm{mA}$ at voltages from $4.5 \mathrm{~V}$ to $36 \mathrm{~V}$. It is designed to drive inductive loads such as relays, solenoids, dc and bipolar stepping motors, as well as other highcurrent/high-voltage loads in positivesupply applications. All inputs are TTL-compatible. Each output is a complete totem-pole drive circuit with a Darlington transistor sink and a pseudo-Darlington source.

\section{BATTERY}

A lithium-ion battery or Li-ion battery (abbreviated as LIB) is a type of rechargeable battery in which lithium ions move from the negative electrode to the positive electrode during discharge and back when charging. Liion batteries use an intercalated lithium compound as one electrode material, compared to the metallic lithium used in a nonrechargeable lithium battery. The electrolyte, which allows for ionic movement, and the two electrodes are the constituent components of a lithium-ion battery cell.

Lithium-ion batteries are common in home electronics. They are one of the most popular types of rechargeable batteries for portable electronics, with a high energy density, tiny memory effect and low self-discharge. LIBs are also growing in popularity for military, battery electric vehicle and aerospace applications.

For notebooks or laptops, lithium-ion cells are supplied as part of a battery pack with 
temperature sensors, voltage converter/regulator circuit, voltage tap, battery charge state monitor and the main connector. These components monitor the state of charge and current in and out of each cell, capacities of each individual cell (drastic change can lead to reverse polarities which is dangerous), and temperature of each cell and minimize the risk of short circuits.

\section{VOLTAGE REGULATOR IC 7805}

Voltage regulator ICs are available with fixed (typically 5V, 6V, 9V, $12 \mathrm{~V}$ etc.,) or variable output voltages. They are also rated by the maximum current they can pass. Negative voltage regulators are available, mainly for use in dual supplies. Most regulators include some automatic protection from excessive current ( "overload protection”) and overheating ('thermal protection').

\section{SOFTWARE REQUIRED}

\subsection{SKETCH}

The Sketch IDE (Integrated Development Environment) is a special program running on your computer that allows you to write sketches for the Arduino board in a simple language modelled after the Processing language. The magic happens when you press the button that uploads the sketch to the board: the code that you have written is translated into the $\mathrm{C}$ language, and is passed to the AVR-GCC compiler, an important piece of open source software that makes the final translation into the language understood by the microcontroller. This last step is quite important, because it's where Arduino makes your life simple by hiding away as much as possible of the complexities of programming microcontrollers.

The programming cycle on Arduino is basically as follows:

Plug your board into a USB port on your computers

Write a sketch that will bring the board to life Upload this sketch to the board through the USB connection and wait a couple of seconds for the board to restart

The board executes the sketch that you wrote. The idea of sketching in code is a way of thinking about writing code as a simple intuitive process, just like drawing in a sketchbook. In this way, an Arduino program is called a sketch and is saved in a folder called a sketchbook. Sketching means we can get our hands dirty and quickly try out a new idea. It is a skill available to all of us.

\section{2 . BLYNK}

Blynk is designed for the Internet of Things. It can control hardware remotely, it can display sensor data, it can store data, visualize it and do many other cool things

There are three major components in the platform:Blynk App - allows to you create amazing interfaces for your projects using various widgets we provide.

Blynk Server - responsible for all the communications between the Smartphone and hardware. You can use our Blynk Cloud or run your private Blynk server locally. Its opensource could easily handle thousands of devices and can even be launched on a Raspberry Pi.

Blynk Libraries - for all the popular hardware platforms - enable communication with the server and process all the incoming and out coming commands.

Easy to integrate and add new functionality using virtual pins

History data monitoring via History Graph widget

Device-to-Device communication using Bridge Widget

\section{ADVANTAGES}

- Wirelesscontrol

- Surveillance system

- Vehicle navigation with use of IOT technology.

- Takes in use of the mobile technology which is almost available everywhere.

VI. DISADVANTAGES

- Battery backup is limited to two hours

- Video is streaming but not recording

VII. APPLICATIONS

- Military operations

- Surveillance along border.

- Search and rescue operation.

- Manoeuvring in hazardous environment.

\section{CONCLUSION}

The primary need for our paper would be accuracy. We have been able to view the things accurately that are currently happening in the surrounding area. Our design has not caused any 
sort of disturbances. The robot will move depending on the motor direction based upon the input we give through command by remote section unit. It display the current operation is going on as example left robot, near to object, clear up. With the help of the camera we are able to view the things that are happening in the surrounding area where the robot is hidden. By keeping the circuit easy and simple, most users will be able to use it easily. Thus we should be able to manipulate its path when necessary, to create the robot safely. To all that, a control unit is needed, where control units IOT signal is used. By using these signals encoding is done \& signal is sent through the transmitter. At the receiver end these decoded signal are given as input to drive the motor. For long range applications it can be used as a spy robot.

\section{REFERENCE}

1. Journal of Network Communications and Emerging Technologies (JNCET) Volume 2, Issue 1, May(2015).AaruniJha, Apoorva Singh, RavinderTurna, Sakshi Chauhan SRMSWCET, UPTU, India (Journal).

2. International Journal of Computer Techniques Volume 3, Issue4, July-Aug2016
SakshiBalasahebChavanke, TejalDnyandev Barhate. Third year Electrical Student, Department of Electrical Engineering, Guru Gobind Singh Polytechnic Nasik Maharashtra, India (Journal).

3. International Journal of Ecology and Development Research IJEDR | Volume4, Issue2, $2016 \quad$ Prof.S.G.Galande ,PawarYogesh, Korade Amit, ChavanJalindar, Associate Professor, E\&TC Dept. PREC, Loni Department of Electronics and Telecommunication Pravara Rural Engineering College, Loni.(Journal).

4. 5th Nirma University International Conference on Engineering (NUiCONE) November 2015 JigneshPatoliya, Haard Mehta , Hitesh Patel, V.T. Patel Department of Electronics and Communication Engineering Charotar University of Science and Technology, Changa, Anand, Gujarat: 388421, India ( Conference ).

5. International Journal of Electrical and Electronics Engineer vol no9, issue no1 2017.Priyanka Yadav, LeenaChaudhari, Swati GawhaleBharatiVidyapeeth College of Engineering, Lavale, India(Journal). 